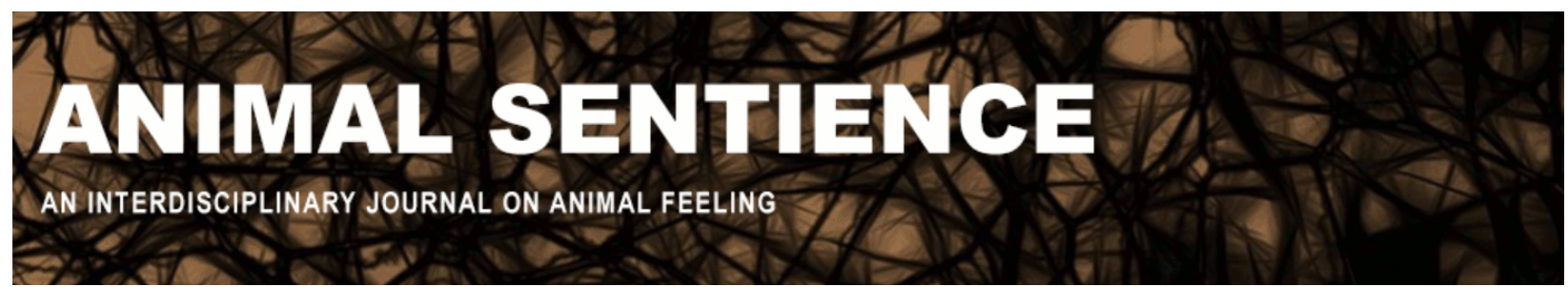

Birch, Jonathan (2018) Degrees of sentience?. Animal Sentience 21(11)

DOI: $10.51291 / 2377-7478.1353$

Date of submission: 2018-06-22

Date of acceptance: 2018-06-28

(c) (i)

This article has appeared in the journal Animal

Sentience, a peer-reviewed journal on animal

cognition and feeling. It has been made open access,

free for all, by WellBeing International and deposited

in the WBI Studies Repository. For more information,

please contact

wbisr-info@wellbeingintl.org.

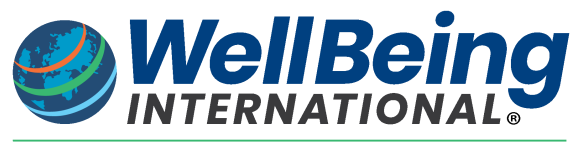

SOLUTIONS FOR PEOPLE, ANIMALS AND ENVIRONMENT 


\title{
Degrees of sentience?
}

Commentary on Sneddon et al. on Sentience Denial

\author{
Jonathan Birch \\ Department of Philosophy, Logic and Scientific Method \\ London School of Economics and Political Science
}

\begin{abstract}
I focus on the possibility of sentience in zebrafish larvae. The evidence here prompts two intuitive reactions that are difficult to reconcile: the reaction that larvae, if sentient, should be protected in some way, and the reaction that larvae, if capable of nociception, should be used as replacements for adults. Both reactions are reasonable, but they can be reconciled only by constructing a framework for assigning degrees of protection in proportion to degrees of sentience.
\end{abstract}

Jonathan Birch is Assistant Professor at the
London School of Economics and Political
Science, specializing in the philosophy of
biology. His book The Philosophy of Social
Evolution was published by Oxford University
Press in 2017. Website

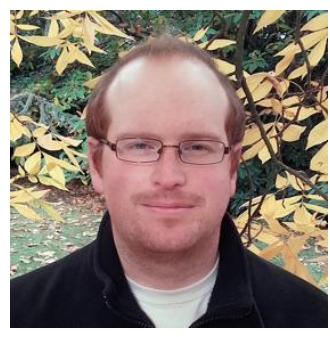

Sneddon et al. (2018) raise a number of important issues relating to fish sentience and fish welfare. The most general issue is whether there is a good scientific case for any kind of sentience in fish. Here I largely agree with Sneddon et al. There is evidence, and it is enough evidence to justify changes to the way we treat fish. There is room for debate about the strength of the evidence in comparison with the evidence of sentience in mammals or birds. But the evidence doesn't have to be particularly strong to justify changes to the way we treat fish, because the way we treat fish creates a serious risk that trillions of animals per year are experiencing avoidable pain and suffering at the hands of humans. Even a small amount of evidence should be enough to convince us to take precautions to mitigate that risk (Birch 2017a,b, forthcoming).

My only disagreement with Sneddon et al. here is terminological: I think the term "fish sentience denial" is too polarizing. It suggests that those sceptical of sentience in fish are extremists who are simply ignorant of the facts (akin to other well-known kinds of "denier"). I don't think they are extremists, nor are they ignorant. Sceptics such as Key (2016) and Rose (2007) deserve respect for their willingness to engage in debate on the issue, even if they have at times been rather dismissive of their opponents. They are certainly sceptics, but "denier" is a much stronger term that should not be used lightly.

A more specific issue - the one I want to focus on - concerns the possibility of sentience in zebrafish larvae. Lopez-Luna et al. (2017a-d) provide evidence that, at only five days postfertilisation ( $5 \mathrm{dpf}$ ), zebrafish larvae respond to noxious stimuli as adults do, and their responses are ameliorated by analgesics as they are in adults. If one takes the responses of adult zebrafish 
to constitute evidence of sentience, one should also take the same responses in the larvae to constitute evidence of sentience. There are two intuitive reactions to this evidence that are difficult to reconcile with each other.

One reaction is that, given this evidence, we should consider replacing adult zebrafish with zebrafish larvae in fish nociception research. This is Lopez-Luna and colleagues' suggestion, and it seems reasonable at face value. The moral case for making such a replacement must rely, at least implicitly, on the assumption that the $5 \mathrm{dpf}$ larvae may be less sentient than the adults in some relevant respects. For example, their experiences of noxious stimuli may be shorter in duration or lower in intensity. They may have less awareness of what is happening to them. Assuming larvae are not used in much larger numbers than adults, there seems to be nothing to lose, in welfare terms, by replacing adults with larvae, and potentially something to gain, if the larvae are indeed less sentient.

The other reaction is that, given this evidence, we should consider bringing $5 \mathrm{dpf}$ larvae within the scope of animal welfare legislation. After all, we protect the adults (in scientific research in Europe, at least) on the basis of similar evidence. If larvae are left unprotected in nociception research, there will be no requirement to count them, and there is a danger that they will be used in much larger numbers than adults would be, and that more severe procedures will be carried out on them. A precautionary approach, which Sneddon et al. support, would seem to justify lowering the threshold for protection from $5 \mathrm{dpf}$ to some earlier developmental stage.

Sneddon et al. offer both reactions in the same paragraph but don't comment on how they relate to each other. There is a tension between them, because bringing $5 \mathrm{dpf}$ larvae within the scope of animal welfare legislation risks disincentivizing the replacement of adults with larvae. The reporting requirements of existing protocols for animal welfare in scientific research are easier to satisfy for adults than for larvae: larvae are harder to count and harder to monitor. The practicality of the recommendation to replace adults with larvae seems to rely on the idea that the larvae are not subject to equally stringent animal welfare protection.

I have noted elsewhere that similar issues arise in relation to decapod crustaceans (Birch 2017a). Protecting decapods at the same level as vertebrates would create a number of practical difficulties for experimental biologists, leading to the argument that protecting decapods would disincentivize justified replacements. But, even granting that there is some truth to this concern, it seems problematic, to say the least, that our way of incentivising justified replacements is to exclude entire orders of potentially sentient animals from the scope of animal welfare law.

In broad terms, a solution to the problem might take the form of a sliding-scale of sentience, with organisms higher-up the scale requiring more stringent levels of protection than those further down. A framework for thinking about degrees of sentience would allow us to argue that zebrafish larvae should be protected in some way, while also arguing that it is appropriate to replace adults with larvae and to apply less stringent controls on the use of larvae.

There is currently no such framework, and it seems to me that developing such a framework should be a major goal of animal sentience research. A critic might object that sentience does not come in degrees - an animal either feels something or nothing, and if it feels something it must be protected. But we can grant this point while acknowledging that, even if the presence or absence of feeling is a binary property, the forms of animal feeling can vary by degrees along multiple welfare-relevant dimensions. 
For example, with regard to pain or pain-like experience (which I take to be just one aspect of sentience), the intensity, duration, salience, accessibility, and motivational force of the experience are gradable. In humans, we have ways of measuring some of these gradations, but they rely on verbal report. The challenge of finding ways to measure these gradations in animals that cannot report their experiences remains a significant methodological hurdle for animal sentience research to overcome.

\section{Acknowledgements}

I thank Reuben Message for discussion of these issues. This work was supported by a Philip Leverhulme Prize from the Leverhulme Trust.

\section{References}

Birch, J. (2017a). Animal sentience and the precautionary principle. Animal Sentience 16(1).

Birch, J. (2017b). Refining the precautionary framework. Animal Sentience 16(20). Birch, J. (forthcoming). Animal cognition and human values. Philosophy of Science.

Key, B. (2016). Why fish do not feel pain. Animal Sentience 3(1).

Lopez-Luna, J., Al-Jubouri, Q., Al-Nuaimy, W. and Sneddon, L. U. (2017a). Activity reduced by noxious chemical stimulation is ameliorated by immersion in analgesic drugs in zebrafish. Journal of Experimental Biology 220: 1451-1458.

Lopez-Luna, J., Al-Jubouri, Q., Al-Nuaimy, W. and Sneddon, L. U. (2017b). Impact of analgesic drugs on the behavioural responses of larval zebrafish to potentially noxious temperatures. Applied Animal Behaviour Science 188: 97-105.

Lopez-Luna, J., Al-Jubouri, Q., Al-Nuaimy, W. and Sneddon, L. U. (2017c). Impact of stress, fear and anxiety on the nociceptive responses of larval zebrafish. PLoS One 12(8):e0181010.

Lopez-Luna, J., Canty, M. N., Al-Jubouri, Q., Al-Nuaimy, W. and Sneddon, L. U. (2017d). Behavioural responses of fish larvae modulated by analgesic drugs after a stress exposure. Applied Animal Behaviour Science 195: 115-120.

Rose, J. D. (2007). Anthropomorphism and 'mental welfare' of fishes. Diseases of Aquatic Organisms 75: 139-154.

Sneddon, L. U., Lopez-Luna, J., Wolfenden, D. C. C., Leach, M. C., Valentim, A. M., Steenbergen, P. J., Bardine, N., Currie, A. D., Broom, D. M. and Brown, C. (2018). Fish sentience denial: Muddying the waters. Animal Sentience 21(1). 


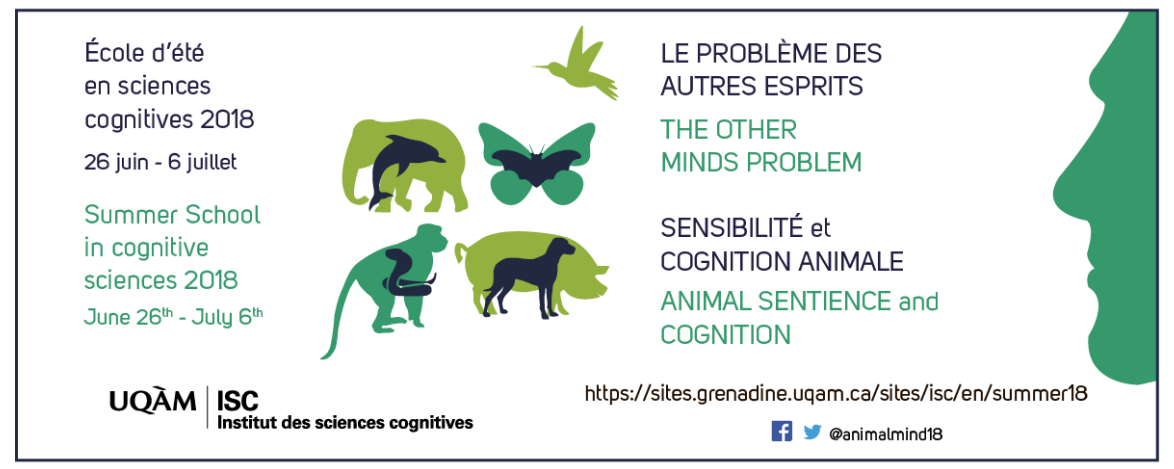

ISC 2018 Summer School in Cognitive Sciences June 26 - July 6, 2018 Montreal (Canada)

\section{The Other Minds Problem: Animal Sentience and Cognition}

Overview. Since Descartes, philosophers know there is no way to know for sure what — or whether — others feel (not even if they tell you). Science, however, is not about certainty but about probability and evidence. The 7.5 billion individual members of the human species can tell us what they are feeling. But there are 9 million other species on the planet (20 quintillion individuals), from elephants to jellyfish, with which humans share biological and cognitive ancestry, but not one other species can speak: Which of them can feel - and what do they feel? Their human spokespersons - the comparative psychologists, ethologists, evolutionists, and cognitive neurobiologists who are the world's leading experts in "mindreading" other species - will provide a sweeping panorama of what it feels like to be an elephant, ape, whale, cow, pig, dog, chicken, bat, fish, lizard, lobster, snail: This growing body of facts about nonhuman sentience has profound implications not only for our understanding of human cognition, but for our treatment of other sentient species.

|Gregory Berns: Decoding the Dog's Mind with Awake Neuroimaging

Gordon Burghardt: Probing the Umwelt of Reptiles

Jon Sakata: Audience Effects on Communication Signals

PANEL 1: Reptiles, Birds and Mammals

WORKSHOP 1: Kristin Andrews: The "Other" Problems: Mind,

Behavior, and Agency

Sarah Brosnan: How Do Primates Feel About Their Social Partners?

Alexander Ophir: The Cognitive Ecology of Monogamy

Michael Hendricks: Integrating Action and Perception in a Small

Nervous System

PANEL 2: Primates, Voles and Worms

WORKSHOP 2: Jonathan Birch: Animal Sentience and the

Precautionary Principle

Malcolm Maclver: $\mathrm{How}$ Sentience Changed After Fish Invaded Land

385 Million Years Ago

Sarah Woolley: Neural Mechanisms of Preference in Female

Songbird

Simon Reader: Animal Social Learning: Implications for

Understanding Others

PANEL 3: Sea to Land to Air

WORKSHOP 3: Steven M. Wise: Nonhuman Personhood

Tomoko Ohyama: Action Selection in a Small Brain (Drosophila

Maggot)

Mike Ryan: "Crazy Love": Nonlinearity and Irrationality in Mate Choice

Louis Lefebvre: Animal Innovation: From Ecology to

Neurotransmitters

PANEL 4: Maggots, Frogs and Birds: Flexibility Evolving

SPECIAL EVENT: Mario Cyr: Polar Bears

Colin Chapman: Why Do We Want to Think People Are Different?

Vladimir Pradosudov: Chickadee Spatial Cognition

Jonathan Balcombe: The Sentient World of Fishes

PANEL 5: Similarities and Differences

WORKSHOP 5 (part 1): Gary Comstock: A Cow's Concept of Her Future

WORKSHOP 5 (part 2): Jean-Jacques Kona-Boun: Physical and

Mental Risks to Cattle and Horses in Rodeos

\author{
Joshua Plotnik: Thoughtful Trunks: Application of Elephant Cognition \\ for Elephant Conservation \\ Lori Marino: Who Are Dolphins? \\ Larry Young: The Neurobiology of Social Bonding, Empathy and \\ Social Loss in Monogamous Voles \\ Panel 6: Mammals All, Great and Small \\ WORKSHOP 6: Lori Marino: The Inconvenient Truth About Thinking \\ Chickens \\ Andrew Adamatzky: Slime Mould: Cognition Through Computation \\ Frantisek Baluska \& Stefano Mancuso: What a Plant Knows and \\ Perceives \\ Arthur Reber: A Novel Theory of the Origin of Mind: Conversations \\ With a Caterpillar and a Bacterium \\ PANEL 7: Microbes, Molds and Plants \\ WORKSHOP 7: Suzanne Held \& Michael Mendl: Pig Cognition and \\ Why It Matters \\ James Simmons: What Is It Like To Be A Bat? \\ Debbie Kelly: Spatial Cognition in Food-Storing \\ Steve Phelps: Social Cognition Across Species \\ PANEL 8: Social Space \\ WORKSHOP 8: To be announced \\ Lars Chittka: The Mind of the Bee \\ Reuven Dukas: Insect Emotions: Mechanisms and Evolutionary \\ Biology \\ Adam Shriver: Do Human Lesion Studies Tell Us the Cortex is \\ Required for Pain Experiences? \\ PANEL 9: The Invertebrate Mind \\ WORKSHOP 9: Delcianna Winders: Nonhuman Animals in Sport \\ and Entertainment \\ Carel ten Cate: Avian Capacity for Categorization and Abstraction \\ Jennifer Mather: Do Squid Have a Sense of Self? \\ Steve Chang: Neurobiology of Monkeys Thinking About Other \\ Monkeys \\ PANEL 10: Others in Mind \\ WORKSHOP 10: The Legal Status of Sentient Nonhuman Species
}

